\title{
Cryopreservation-Induced Stress on Long-Term Preserved Articular Cartilage
}

\author{
Rajdeep Kaur, ${ }^{1}$ K. Pramanik, ${ }^{1}$ and S. K. Sarangi ${ }^{2}$ \\ ${ }^{1}$ Department of Biotechnology and Medical Engineering, NIT Rourkela, Odisha 769008, India \\ ${ }^{2}$ Department of Mechanical Engineering, NIT Rourkela, Odisha 769008, India \\ Correspondence should be addressed to K. Pramanik; kpr@nitrkl.ac.in
}

Received 4 June 2013; Accepted 20 June 2013

Academic Editors: X. Jiang and A. Vallés-Lluch

Copyright (c) 2013 Rajdeep Kaur et al. This is an open access article distributed under the Creative Commons Attribution License, which permits unrestricted use, distribution, and reproduction in any medium, provided the original work is properly cited.

\begin{abstract}
Tissue engineered cartilage constructs have potential clinical applications in human healthcare. Their effective utilization is, however, hampered by the lack of an optimal cryopreservation procedure that ensures their availability as and when required at the patient's bedside. Cryopreservation-induced stress represents a major barrier towards the cryopreservation of such tissue constructs, and they remain a scientific challenge despite the significant progress in the long-term storage and banking of isolated chondrocytes and thin cartilage tissue slices. These stresses are caused by intra- and extracellular ice crystallization, cryoprotectant (CPA) toxicity, suboptimal rates of cooling and warming, osmotic imbalance, and altered intracellular $\mathrm{pH}$ that might cause cellular death and/or a disruption of extracellular matrix (ECM). This paper reviews the cryopreservation-induced stresses on tissue engineered cartilages and discusses how they influence the integrity of the tissue during its long-term preservation. We have also reported how various antioxidants, vitamins, and plant extracts have been used to inhibit and overcome the stress during cryopreservation and provide promising results. Based on the reviewed information, the paper has also proposed some novel ways which might help in increasing the postthawing cell viability of cryopreserved cartilage.
\end{abstract}

\section{Introduction}

Defects and diseases of articular cartilage are common ailments in humans. Osteoarthritis, the most common form of arthritis involving the inflammation of the articular cartilage, is observed in $60-70 \%$ of the people above the age of 65 [1]. In the USA alone, over 27 million people are known to be suffering from these articular defects [2]. Cartilage also has a limited regeneration capacity, and hence, available therapeutic modalities provide a temporary relief and have a limited clinical success. In recent years, with the rapid advancement in the tissue engineering, artificial cartilages engineered from biopolymers and stem cells have shown promising clinical results, and therefore, they have been envisaged as a future therapy for an effective and long-term clinical outcome.

Preservation of tissue engineered articular cartilage is also essential for their widespread commercialisation so that they can be provided to patients as and when required. The growing need and limited availability of viable transplantable cartilaginous tissues have necessitated the development and optimization of the preservation techniques and banking of tissue engineered cartilage constructs. Preservation of tissue engineered constructs also enables the tissue to undergo extensive immunological testing, size/contour matching, and optimal timing for supply whenever demanded by patient or surgeon [3].

There are various techniques of cryopreservation such as preserving at $4^{\circ} \mathrm{C}$ to $-80^{\circ} \mathrm{C}$ and storing by a controlled rate freezing, or by plunging in LN2, by vitrification (Table 1). However, currently long-term preservation of tissue engineered cartilage is achieved by two common methods: controlled-rate freezing and vitrification [11, 12]. The vitrification method of preserving tissue engineered cartilage is very efficient in tissue preservation but carries a toxicity risk, and thus, could be hazardous to the patient. High-concentration of CPA and CPA toxicity may affect the structural integrity and functionality of the tissue. It 
TABLE 1: Existing methods for the cryopreservation of tissue engineered constructs.

\begin{tabular}{|c|c|c|c|c|c|c|}
\hline $\begin{array}{l}\text { Preservation } \\
\text { method }\end{array}$ & $\begin{array}{c}\text { Storage } \\
\text { temperature }\end{array}$ & $\begin{array}{l}\text { Storage } \\
\text { medium }\end{array}$ & $\begin{array}{c}\text { Duration of } \\
\text { storage }\end{array}$ & Advantage & Disadvantage & Reference \\
\hline $\begin{array}{l}\text { Domestic } \\
\text { freezer }\end{array}$ & $4^{\circ} \mathrm{C}$ & $\begin{array}{l}\text { Culture } \\
\text { medium } \\
\text { often without } \\
\text { any addition } \\
\text { of CPA }\end{array}$ & 14-28 days & $\begin{array}{l}\text { No ice crystal formation, } \\
\text { no CPA addition }\end{array}$ & $\begin{array}{l}\text { Short storage period } \\
\text { which is insufficient to } \\
\text { carry out immunological } \\
\text { and biomechanical } \\
\text { assays which are to be } \\
\text { carried before } \\
\text { transplantation, } \\
\text { decrease in cellular } \\
\text { activity with an increase } \\
\text { in time }\end{array}$ & $\begin{array}{c}\text { Bae et al., } 2009[4] \\
\text { Williams et al., } 2003 \\
\text { [5] }\end{array}$ \\
\hline Deep freezer & $-80^{\circ} \mathrm{C}$ & $\begin{array}{c}\mathrm{CPA} \text { or } \\
\text { without } \mathrm{CPA}\end{array}$ & $30-60$ days & $\begin{array}{l}\text { No complex device } \\
\text { required, low running } \\
\text { cost }\end{array}$ & $\begin{array}{l}\text { Critical temperature for } \\
\text { preservation of the 3D } \\
\text { construct and the } \\
\text { sensitive cells seeded on } \\
\text { it, uncontrolled freezing, } \\
\text { ice crystals formation }\end{array}$ & Bakhach, 2009 [6] \\
\hline $\begin{array}{l}\text { Controlled rate } \\
\text { freezing }\end{array}$ & $\begin{array}{l}\text { A stepwise } \\
\text { method can be } \\
\text { up to }-150^{\circ} \mathrm{C}\end{array}$ & $\begin{array}{l}\text { CPAs are } \\
\text { added }\end{array}$ & $\begin{array}{l}\text { As long as } \\
\text { desired when } \\
\text { sample is } \\
\text { plunged in } \\
\text { LN2 }\end{array}$ & $\begin{array}{l}\text { Low concentration of } \\
\text { CPA, cooling is carried } \\
\text { out at a constant cooling } \\
\text { rate so as to cause } \\
\text { minimum damage to the } \\
\text { tissue, allows the cells to } \\
\text { dehydrate in equilibrium } \\
\text { with the partially frozen } \\
\text { cryoprotectants and } \\
\text { other extra solutions } \\
\text { present in the } \\
\text { suspension }\end{array}$ & $\begin{array}{l}\text { Optimized protocols } \\
\text { required for each } \\
\text { biological product, } \\
\text { needs a skilled and } \\
\text { experienced person to } \\
\text { handle the entire process } \\
\text { so that cooling is } \\
\text { optimized enough to } \\
\text { allow water to efflux out } \\
\text { from the cell during } \\
\text { extracellular ice } \\
\text { formation }\end{array}$ & Enneking, 1991 [7] \\
\hline $\begin{array}{l}\text { Liquid nitrogen } \\
\text { LN2 }\end{array}$ & $\begin{array}{l}\text { Ultra low } \\
\text { temperature } \\
-196^{\circ} \mathrm{C}\end{array}$ & $\begin{array}{l}\text { CPAs are } \\
\text { added }\end{array}$ & $\begin{array}{l}\text { As long as } \\
\text { desired with } \\
\text { reliable LN2 } \\
\text { back up }\end{array}$ & $\begin{array}{l}\text { Rapid cooling method, } \\
\text { simple handling, } \\
\text { mechanically reliable }\end{array}$ & $\begin{array}{l}\text { Risk of contamination } \\
\text { via LN2, LN2 is costly; } \\
\text { therefore, a high running } \\
\text { cost as regular supply of } \\
\text { LN2 is required }\end{array}$ & $\begin{array}{c}\text { Salai et al., } 1997 \text { [8], } \\
\text { Cetinkaya and Arat, } \\
2011 \text { [9] }\end{array}$ \\
\hline $\begin{array}{l}\text { Vapour phase } \\
\text { LN2 }\end{array}$ & $\begin{array}{l}\text { Temperature } \\
\text { below }-150\end{array}$ & $\begin{array}{l}\text { CPAs are } \\
\text { added }\end{array}$ & $\begin{array}{l}\text { As long as } \\
\text { desired with } \\
\text { reliable LN2 } \\
\text { back up }\end{array}$ & $\begin{array}{l}\text { Eliminate the risk of } \\
\text { cross-contamination } \\
\text { from other samples and } \\
\text { microbes }\end{array}$ & $\begin{array}{l}\text { Vapour phase varies } \\
\text { from protocol to } \\
\text { protocol and the } \\
\text { geometry of the tissue, } \\
\text { there is often } \\
\text { temperature fluctuation } \\
\text { within the vapour phase, } \\
\text { volume occupied within } \\
\text { the container is } \\
\text { nonplanned, regular } \\
\text { supply of LN2 is required }\end{array}$ & $\begin{array}{l}\text { Tissue engineering } \\
\text { Clemens van } \\
\text { blitterswijk—chapter } \\
13 \text { by Lilia Kuleshova } \\
\text { and Dietmar } \\
\text { Hutmacher [10] }\end{array}$ \\
\hline
\end{tabular}

may also result in immune reactions and carcinogenesis when inserted into the host. A combination of penetrating and nonpenetrating CPAs which are considered to be less toxic is also required in high concentrations which may lead to conditions, of acidosis and osmotic stress in the tissue and can also induce mutational changes due to the chemical reactions amongst the CPAs themselves. Similarly, controlled rate freezing or slow freezing method, which uses low concentration of CPA and gradually cools the tissue in a stepwise manner, though may sound to be attractive, has its own disadvantages and often results in extreme cellular dehydration. Moreover, cryopreservation has been effective to some extent but only for the long-term preservation of cells. Cryopreservation of tissue engineered construct is not a simple affair; the already established protocols for the cryopreservation of cells cannot be simply implied for the preservation of complex tissue engineered constructs. The tissue engineered cartilaginous construct which consists of several chondrocytes surrounded by a unique extracellular matrix and a framework or scaffold on which the tissue grows and releases cartilage specific matrix proteins are far more difficult to preserve compared to cells and monolayer cultures. 


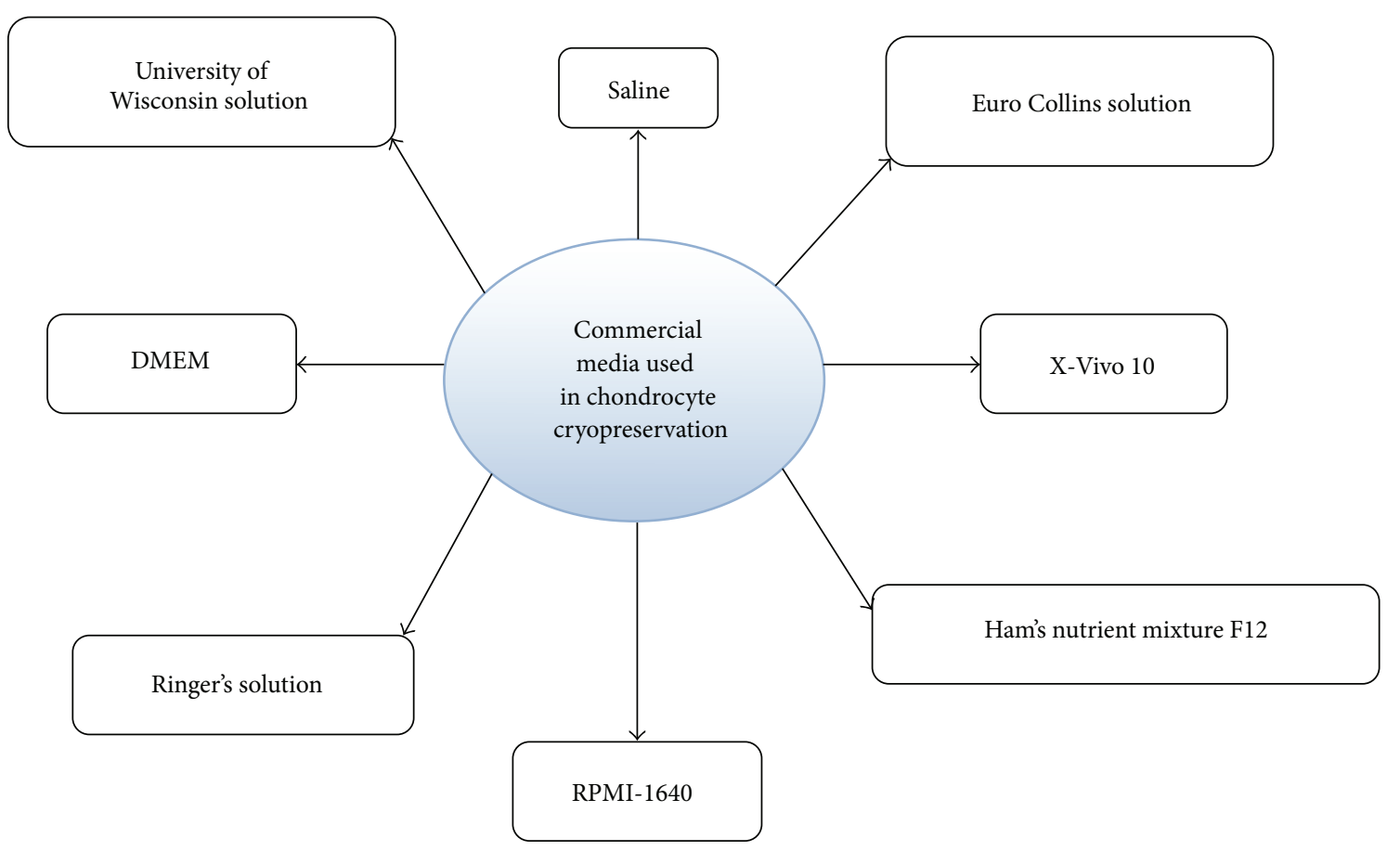

FIgURE 1: Commercial media used in cryopreservation of cartilage.

The methods that have been successful in the preservation of cells may not maintain the same output when subjected to tissue engineered constructs. Therefore, in recent years, cryopreservation methods and outcomes have stimulated a strong curiosity among researchers and scientists due to their ease in manufacturing, storage, handling, and recovering when required (Figure 1). On the other hand, another major cause for the increasing curiosity among the researchers is the poor outcome in the viability and functionality of the tissue engineered cartilage construct after cryopreservation. Though transplantation of preserved cartilage is thought to have a great role in regenerative medicine, there are various conflicting views and deviating opinions regarding the outcome of the cryopreserved cartilage [13-15].

Many researchers have addressed the complexity and difficulty in the cryopreservation of tissue engineered cartilages which continues to remain a challenge [15-17] due to the potential interaction of the scaffold material and tissue matrix $[15,18-24]$. Several stresses causing conditions such as anoxia, intra- and extracellular ice crystallization, poor permeation of the CPA, CPA toxicity, suboptimal rates of cooling and/or warming, osmotic imbalance, altered intracellular $\mathrm{pH}$, nutrient depletion, and withdrawal of essential growth factors are believed to be responsible for the lowered viability of cryopreserved cartilages. These conditions induce various physiochemical, biochemical, and mechanical stresses on the cartilage. These stresses can induce variety of changes in the cartilage matrix and can also activate the cell death pathway like apoptosis or necrosis and ultimately causing construct failure [17].

In many cases, it is believed that when a cell commits to cell death, first apoptosis is activated and continues via the classical apoptotic pathway till the stress experienced by the cell exceeds the normal limits or the energy reserves become too low for apoptosis to continue. It is at this point that the cell switches from apoptotic to necrotic pathway (causing secondary necrosis) [25-27]. This paper, highlights and discusses the cryopreservation-induced stresses on tissue engineered cartilage construct by further targeting and inhibiting the molecules playing an important role in bringing cell death, thereby improving the cryopreservation outcome.

\section{Types of Stresses Faced by Tissue Engineered Cartilage Construct during Cryopreservation}

2.1. Physiochemical Stress. The physiochemical environment within the engineered cartilage is determined by various parameters such as matrix hydration, interstitial ion concentration, fixed charge density, and activity coefficients for specific ions within the extracellular matrix (ECM) of the cartilage [28] which controls the permeability, diffusivity, and streaming potential of the chondrocytes [29]. Cartilages provide a specialized physiochemical environment to the homing chondrocytes and determine the viscoelastic and physical properties of the tissue [30]. The metabolic activity of these cells is highly influenced by biological factors such as ionic concentration and matrix composition. As the tissue engineered cartilage construct is sensitive and fragile the microenvironment of each cell should remain physiologically yet dynamically maintained in an intact, functional, and wellpreserved cartilage construct. However, during freezing and 
thawing, a series of processes occur in the local surrounding of the cartilaginous construct that cause physiochemical stress on the delicate tissue. The changes in the physiochemical environment can also modulate the metabolic response of chondrocytes, whether the cell is in the native tissue or in an engineered construct [31].

\subsubsection{Physiochemical Stress due to Ice Crystallization. In} healthy cartilage water, along with other extracellular components, a gel-like matrix is formed which helps the cartilage to perform its function of shock absorption. In diseases such as osteoarthritis much of the water is lost from the cartilage. Similar loss of water is also observed during the cryopreservation of cartilages. The formation of extra-cellular ice crystals during freezing compresses the tissue leading to the exudation of water from the tissue. Release of water from the cells and the ECM of the cartilage strongly affects the transportation of ions and interferes with the physiochemical environment of the tissue. With the increasing loss of water the concentration of proteoglycans inside the tissue goes on increasing; as a result, the fixed charge density and associated interstitial ions also increase [30,32]. Scientists have reported that these changes within the tissue can induce a change in the cell shape and volume $[33,34]$. Cryopreservation-induced volumetric and structural changes in the chondrocytes also exert a strong influence on their biosynthetic activity. Schiller et al. [35] reported a decrease in the rates of the synthesis of various metabolic products such as aggrecan, collagen, and noncollagen proteins and various other metalloproteinases [35]. Long-term cryopreservation also causes changes in other matrix macromolecules such as cartilage oligomeric matrix protein [36]. These changes make the cartilage construct weaker and its physiochemical properties poorer in comparison to the native cartilage.

An immense loss of water from the tissue also causes a breakdown in the proteoglycan aggregates to which chondroitin and keratin sulphate GAG chains are attached making the tissue saggy [37-40]. These undesirable changes in the local environment along with the compression caused by the extra-cellular ice crystals may also modify the mechanical behaviour of the tissue, as the physicochemical factors have a strong relation with the material parameters such as hydraulic permeability [28]. Since the articular cartilage is avascular and receives its nutrition only through the synovial fluid, then when such a stressed cartilage is transplanted into the load bearing sites, diffusion of nutrients into the deeper regions is deprived, leading to the degradation and necrosis of the sensitive chondrocytes present in the delicate tissue engineered cartilage construct.

2.1.2. Physiochemical Stress due to Osmotic Imbalance. Tissue engineered cartilaginous scaffolds already have various problems associated with biocompatibility, biodegradability, and self-assembling. Such constructs during the process of freezing and thawing further undergo an immense stress from which the fragile constructs are not able to shield themselves especially from the changes in osmotic pressure which makes the subtle tissue on the scaffold susceptible to swelling and cellular deformation [41]. During freezing, the formation of extracellular ice takes place. Pure water freezes first leaving behind a concentrated fluid of ions, salts, and other proteins. This leads to the development of a concentration gradient between the intra- and extracellular spaces of the tissue. Changes in the $\mathrm{pH}$ conditions have a potential effect on cellular functions [42]. Any change in the ability of the cell to maintain its intracellular $\mathrm{pH}$ may affect the functioning of the chondrocytes including the synthesis of the matrix. There are various studies that have shown that osmotic stress and fluid flow alter the calcium level of chondrocytes. Calcium plays a major role in the physiological conditions. An alteration in the Ca levels in the cartilage can affect the synthesis.

During extracellular ice formation, the extracellular fluid becomes acidic, and the water from the tissue squeezes out to maintain the concentration gradient, reducing the net content of free water within the tissue. The flow of intra cellular and intramatrix water out of the tissue generates an increased osmotic pressure within the tissue which may lead to the formation of fissures. These fissures may later develop into sites of cell necrosis after thawing. Initially, it is only in the inner and middle layers of the cartilage, which gradually develops towards the articular surface.

It has been also reported by various researchers that extracellular $\mathrm{pH}$ is a significant regulator of cartilage matrix metabolism and activity of various enzymes. A slight change in the extracellular $\mathrm{pH}$ (less than 6.9) may significantly inhibit the matrix synthesis rate up to $50 \%$ [43].

Acidic $\mathrm{pH}$ conditions also activate various degradative enzymes. Example of such an enzyme is cathepsin $\mathrm{K}$ that shows an increased proteolytic activity in acidic environment. Cathepsin K can cleave the triple helix of collagen type I and II. Cathepsin $\mathrm{K}$ is also the only enzyme of the cytkosine protease family known to cleave the telopeptide domains as well as the $\alpha$ chain present in various sites of the fibrillar network of cross-linked collagen. Cleavage of telopeptides causes the depolymerisation of fibrillar collagen network, and cleavage of the triple helix present in collagen results in depolymerisation accompanied by denaturation [44].

2.1.3. CPA Induced Physiochemical Stress. CPA addition or removal is one of the most crucial steps in the cryopreservation of cells, natural tissue, or engineered constructs. The presence of CPA induces a series of solution effects and chemical toxicity that cause chemical stress to the cell. CPAs usually have a concentration higher than that of the intracellular fluid when added to the tissue also causing a hypertonic shock for the cell resulting in an osmotic stress on the cells and the extracellular matrix. The cell shrinks necessitating the membrane to contract. Hypertonic shock triggers the activation of many ion channels and transporters (PMCA, NCX, NKCC etc.,) which may change the biosynthetic activity of the cell. They pump in large concentrations of $\mathrm{Ca}, \mathrm{Na}, \mathrm{K}$, and $\mathrm{Cl}$ inside the cell, thereby increasing the ionic concentration of the cell. The intracellular $\mathrm{pH}$ of the cell decreases leading to an acidic condition inside the cell, and $\mathrm{pH}$ is also altered during the removal of the CPA resulting in an increase of $\mathrm{pH}$. Furthermore due to cellular shrinkage multiple ion channels 
of the chondrocytes are known to undergo conformational changes. Abnormal morphology of the chondrocytes is a sign of cartilage degradation and cellular apoptosis. Extreme physiological conditions such as osmotic pressure, cellular shrinkage, and the increase in intra cellular Ca seem reasonable during the process of cryopreservation though they are the symptoms of cartilage degradation. Even intracellular cryoprotectants which remain in the cells after thawing are known to be toxic as they disrupt the acid-based equilibrium of the cell. Thus, CPA can damage the cell either due to the osmotic stress it renders on the cell, or due to the toxicity of the cryoprotectant itself.

Physiochemical stress can be prevented by controlling the ice crystallization and creating an osmotic balance within the cell and its surrounding ECM. Zheng et al. [45] reported that cryopreservation through rapid cooling may be preferred for tissue engineered cartilage. In case of rapid cooling, the chondrocytes are unable to lose the intracellular cytoplasmic fluid at the rate they did in case of slow cooling, and therefore, ice formation is markedly reduced ice formation [46]. A high cooling rate also delays molecular diffusion and blocks the transition from a liquid to a solid crystalline state. Consequently, the intracellular fluid turns in an amorphous state rather than a solid crystalline state, and therefore, theoretically the crystallization of tissue engineered cartilage can be prevented by using a relatively rapid cooling $[6,46]$. Increasing the viscosity of the liquid phase is yet another plausible method of preventing the ice crystallization and, hence, the physiochemical stress on the tissue engineered articular cartilages. In addition, a CPA that does not react with the $3 \mathrm{D}$ construct preserves the chondrocytes and maintains the integrity of the matrix that should be chosen. However, none of the known CPAs are specific for cartilage cryopreservation.

2.2. Biochemical Stress. Chondrocytes are the only cell type present in the cartilage and are responsible for the synthesis and degradation of the articular cartilage matrix. For tissue engineered cartilage to be successful for clinical applications, the chondrocytes in the engineered cartilage should be able to synthesize normal ECM which primarily contains large aggregating proteoglycans such as aggrecan, type II collagen, and water. The type II collagen network provides strength to the cartilage while hydrated proteoglycans provide compressive resistance [47]. The ECM also regulates intracellular communication, controls cell dynamics, and releases all the essential growth factors. Any change in the intracellular composition of the chondrocyte may prove to be fatal for the entire matrix synthesized. For example, the $\mathrm{Na}$ and $\mathrm{K}$ ions help various membrane transport proteins to carry out a variety of physiological functions such as $\mathrm{pH}$ regulation, uptake of sugars, and amino acids. In cartilage, the $\mathrm{Na}$ and $\mathrm{K}$ ion pumps are maintained by the ionic composition of the ECM and are sensitive to both ionic and osmotic changes of the intra- and extracellular composition of the cell [48]. The biochemical composition of a tissue engineered cartilage also plays an important role in preserving the tissue integrity and its mechanical properties $[49,50]$.
However, freezing and thawing is known to affect the biochemical properties of the engineered cartilage. Cryopreservation usually results in changes at the molecular, cellular, and tissue levels besides causing changes in hydrostatic pressure gradient and fluid flow which in turn can modify the synthesis and/or degradation of the macromolecules present in the extracellular matrix [41]. Cryopreservation changes the intra- and extracellular environment of the tissue by increasing the ionic concentration and inducing osmotic stresses. The intra- and extracellular $\mathrm{pH}$ also changes during the process of cryopreservation. These stresses destroy the membrane permeability and the integrity of the cell membrane; they destroy various membrane transport pumps such as the Na, K pumps present on the cell membrane, and cause irreversible denaturation of various proteins. Other cryopreservation-induced biochemical alterations reported in the tissue engineered cartilage include the damage to proteins like annexin $\mathrm{V}$ receptors which play an important role in collagen binding and cartilage metabolism [51-53].

2.2.1. Biochemical Stress due to Ice Crystallization. Ice crystallisation results in the increase of the ionic concentration of ECM and, hence, changes the chemical environment of the cell and its ECM. Various transport pumps present on the cell membrane that are sensitive to ionic and osmotic changes are denatured, and thus, membrane integrity gets destroyed. The intracellular organelles also get denatured due to changes in the ionic concentration, leading to cell membrane deformation and the initiation of cell death pathway. Extracellular ice is also reported to destroy the cell receptors present on the membrane of the chondrocytes. Formation of ice leads to the increase in the concentration of salts that denatures many proteins and lipoproteins. Integrins ( $\beta$-1 subfamily) which are special receptors present on the cell membrane of the chondrocytes that help the cell for various important biochemical reactions such as cell matrix interaction, proliferation, attachment to the scaffold, differentiation, and survival are reported to be damaged by the process of cryopreservation. This, in turn, induces a biochemical stress on the cell, thereby preventing the cell from and further differentiation and directing the cell to the apoptotic pathway. Investigators have also reported that $\beta-1$ deficient chondrocytes have an abnormal phenotypic character and the loss of ability to adhere to type II collagen after cryopreservation [51, 52].

2.2.2. Biochemical Stress due to CPA. Biochemical stress may also be induced by the CPAs themselves. Many CPAs can block the ion channels and can imbalance the physiological ion homeostasis. Certain CPAs such as DMSO block the $\mathrm{Ca}^{+}$ and $\mathrm{Na}^{2+}$ ion channels within the chondrocyte membrane and alter the mithocondrial membrane potential to cause the mithocondrial dysfunction. These events aid in the slowing down of the cellular processes related to energy production, free radical detoxification, and maintenance of the chondrocytes. Mitochondrial dysfunction may also cause apoptosis, aging, and other cytopathic conditions leading to tissue destruction [54]. Thus, CPAs can reduce the cellularity 
and matrix content of the engineered cartilage constructs by causing biochemical stress $[15,51,55]$. The presence of CPA is also known to cause a chemiosmotic stress on the cartilage which finally results in morphological and functional damage to the cells causing subsequent necrosis.

2.2.3. Biochemical Stress due to Thermal Shock. During cryopreservation of tissue engineered cartilaginous constructs, usually uneven cooling occurs due to complex nature of the scaffold. In such a condition, when the temperature is reduced from 35 to $15^{\circ} \mathrm{C}$ or 0 to $-80^{\circ} \mathrm{C}$, a series of chemical changes occur in the components of the ECM and the cellular membrane causing cell membrane lesions. This extreme change in temperature from normal physiological temperature to subzero causes a thermal shock to the tissue. It also causes ionic and hydraulic imbalance in the cell. Even in the absence of any intra- or extracellular ice this shock may cause a graft failure.

Furthermore, changes in the template of temperature cause various alterations in the ionic composition of the extracellular medium of the chondrocytes. Imbalance in the concentration of anions such as acetate, chloride, nitrate sulphate, and phosphate anions is another contributing reason for cell membrane damage [6]. There are various theories which have proven that a change in the circulating level of phosphate causes hypertonic chondrocyte apoptosis. On supplying additional phosphate for treatment of the cell it results in the activation of mitochondrial apoptotic pathway [56].

Cryopreservation protocols, thus, need to be developed if the biochemical properties of the chondrocytes and the extracellular matrix are to be preserved. One approach is to add various nutrients and growth factors to the culture medium to provide a fast recovery of the cryopreserved chondrocytes [51]. Loading of CPAs in the right amount is also an acceptable method to reduce biochemical stress. Furthermore, various CPAs are added in lower concentration forming a CPA cocktail, which is found to be significantly less toxic than a single CPA solution in the same total concentration [57]. Addition of antishock proteins, antioxidants, and other specific phospholipids with a slow uniform cooling may also be a potential method for reducing the biochemical stress. Certain changes may also be made in the chemical composition and properties of the 3D scaffold for better cell proliferation and migration. The topography of the scaffold may also be modified (surface modification) by different techniques for better cell attachment.

2.3. Mechanical Stress. Cryopreservation-induced mechanical stress on tissue engineered cartilage is one of the least studied areas in the field of cryopreservation. It can result from the physiochemical and biochemical events that occur during the process of cryopreservation. There are a few studies that have recently reported the microstructural changes and ECM swelling of the tissue along with the unequal distribution of interstitial fluid after thawing [41, 47]. Biomechanically, the collagen content provides a structural framework for the tissue, while the GAG content is responsible for the mechanical stiffness of the tissue as a load-bearing media. Both collagen and the GAG in the cartilage are also found in reduced quantities in cryopreserved cartilage. Thus, the engineered cartilage becomes mechanically weakened after the freezing and thawing process and their mechanical properties are compromised [38, 58-61].

Although the mechanism is yet to be fully understood [30], recent reports suggest that ice crystallization and osmotic imbalance are the two main reasons for the mechanical stress on the cell membrane and the ECM which, thereby, leads to deformation $[6,62]$. Since tissue engineered cartilage loses heat at a lower rate at its centre than its edge, the rate of cooling does not occur uniformly throughout the tissue and affects the formation of ice during the freezing [63]. The differential ice crystallization within the tissue imparts a mechanical difference, and thereby, causes a mechanical stress on the physiology of the engineered cartilage [63]. With the progression in the differential ice formation across the tissue, a differential osmotic gradient is also created which further generates a mechanical force that disrupts the cartilaginous tissue.

2.3.1. Mechanical Stress due to Ice Crystallization. Mechanical injuries are obviously occuring due to intra- or extracellular ice crystal formation. Ice crystallization is known for its activation of stressors such as osmotic shock, hypothermia, ischemia, and ionic dysregulation which trigger necrosis. In cartilage cryopreservation, ice crystals have been reported to disrupt the extracellular matrix of the articular cartilage [38]. The profile of GAG distribution in cartilage which is highest at the centre and lowest at the superficial layer gets significantly reversed on freezing-thawing the cartilage. The crystallisation of ice breaks down the proteoglycans which are composed of several GAGs, predominantly the chondroitin sulphate and keratin sulphate GAGs. The small broken chains of GAG diffuse out from the ECM due to strong electrostatic repulsions among the negative charges inside the tissue. This reduces the concentration of GAG present in the ECM of the cartilage resulting in a degraded cartilage which is mainly proteoglycan depleted. This causes a severe physical injury to the tissue, thereby decreasing its mechanical modulus.

In certain cases when rate of growth of ice is dependent on the rate of diffusion of solutes away from the ice front, a slight decrease in the temperature may lead to an amplified supercooling of the inner mass of the tissue leading to sudden unplanned nucleation at various positions within the matrix and also leads to the formation of a lesion.

2.3.2. Mechanical Stress due to CPA Loading and Unloading and Resultant Osmotic Imbalance. The addition of cryoprotectants and their removal are two crucial procedures followed during the cryopreservation of tissue engineered cartilage constructs [64]. The optimal cryopreservation of tissue engineered cartilage construct requires a clear understanding of the sequence and manner these CPAs distribute themselves into the construct. Dehydration of the cells, cellular shrinkage, changes in the extra- and intracellular osmolality, and intracellular $\mathrm{pH}$ changes are common during 
CPA loading and unloading. Freezing and thawing process in turn has a major effect on chondrocyte survival, tissue physiology, and morphology. It also causes osmotic and mechanical stresses on the matrix of the cartilage resulting in poor mechanical properties of the tissue.

During CPA loading, there is an increase in the ionic concentration of the fluid outside the cells. Chondrocytes osmotically respond to the increasing concentration of extracellular fluid by ejecting out most of the interstitial fluid present. Movement of the intracellular fluid out of the cell leads to cell shrinkage and ultimately dehydrates the cells. This also results in an increase of the intracellular $\mathrm{pH}$, and as most of the interstitial fluid flows out of the cations, the fixed charges get concentrated within the chondrocytes [64]. The increased ionic concentration causes severe osmotic shrinkage, thereby making the chondrocytes more vulnerable to permanent cellular damage. However, when CPA starts diffusing into the cells the outflowing interstitial fluid slows down. Eventually, as more and more CPAs penetrate into the cell, the outflow of interstitial fluid through the membrane is stopped and the direction of the flow is reversed. This causes the swelling of the membrane of the chondrocytes, thus swelling the cartilage tissue itself. This shrinkage and swelling of cellular volume also damages the chondrocyte matrix attachment which annihilates the normal functioning of the cartilage. Cell matrix attachments are also expected to be lost after cryopreservation.

The reverse mechanism occurs during CPA unloading. The ionic concentration of the fluid outside the tissue is far less compared to the concentration of the interstitial fluid. The ionic concentration gradually increases as more and more faces a gradual increase as more and more fluids from the surrounding tissue penetrate into the cell to osmotically balance the fluid conditions across the membrane [64, 65]. This often causes cell burst. This stress and strain on the cell results in a weathered cell membrane.

2.4. Oxidative Stress. Cartilage is an avascular tissue, and as a result the oxygen transport of matured cartilage is reduced compared to vascularised tissues. Despite the minimal consumption of oxygen by cartilage, oxygen is an essential requirement for the chondrocytes to survive and carry out other metabolic activities. Freezing the cartilage resists the delivery of oxygen and essential nutrients, removal of waste, and cell to cell communication. Under low oxygen conditions the ATP level of the cells, glycolysis, and matrix production also fall, damaging the cell physicochemical reactions. Low oxygen conditions are also known to damage the glucose transporters that cause changes in the synthesis of the extracellular matrix [66], growth factors, expression of mRNA, and integrins in cartilage.

Another kind of oxidative stress is caused by the reactive oxygen radicals released during the freezing and thawing process. Reactive oxygen species (ROS) inhibit the synthesis of the proteoglycan by the chondrocytes, collagen and hyaluronic acid, and ECM degradation and initiates the release of LDH by damaging the cell membrane and damaging various transporters and pathways and depressing its metabolic pathway for energy production. A damage caused to chondrocyte membrane during freezing and thawing also transfers the cellular membrane injury to the mitochondria through the cytoskeleton. The mitochondria in turn releases ROS in high amount causing chondrocyte death and ECM degradation. ROS scavengers superoxide dismutase is reduced in the cryopreserved cartilage. Levels of ROS have been found to be greater in the cartilage of the people suffering from joint diseases [67]. It is also a major cause of cell necrosis. ROS, thus, may have an unfavourable effect on tissue engineered cartilage preservation. ROS affects the overall material properties of the tissue engineered cartilage and influences its ability to respond to various stresses. Therefore, decreasing oxidative stress is likely to be beneficial to cryopreserved cartilage.

Excess of ROS and oxidative stress trigger the mitochondrial or intrinsic apoptotic pathway of cell death. These stresses stimulate the opening of mitochondrial permeability transition pore (MPT). The opening of MPT causes loss in mitochondrial membrane potential and finally leading to the release of various proteins into the cytosol. Cytochrome $\mathrm{c}$ is an example of one such protein released by mitochondria, which may cause the release of apoptogenic proteins, such as cytochrome $c$, from mitochondria $[68,69]$. These proteins transduce the apoptotic signal via the caspase-dependent pathway, which leads to morphological changes associated with apoptosis. The permeabilization of the mitochondrial membrane is regulated by the BCL- 2 class of proteins which thereby regulate the activation of the caspase. Targeting and silencing the proapoptotic members of the BCL-2 family may block the cryopreservation induced apoptosis.

2.4.1. Use of Cryoprotectants. A number of cryoprotectants have been discovered since 1949, when Polge Smith and Parks discovered the cryoprotective nature of glycerol for bull sperms [70]. Cryoprotectants are mainly of two types the permeating and the nonpermeating cryoprotectants. Non permeating cryoprotectants include starches, such as hydroxyl ethyl starch, sugars, such as dextrose, glucose and sugar alcohols, such as erythritol, and sorbitol, and other compounds such as polyvinylpyrrolidone. The role of nonpermeating cryoprotectants is mainly cell membrane preservation. These large molecules exert a colloidal osmotic pressure, thus rendering support to the cell membrane. These molecules also form a hydrogen bond with the unfrozen intracellular water, thereby altering its activity and preserving the cell membrane. Permeating cryoprotectants such as DMSO, Glycerol, and Ethylene glycol are small molecules that can penetrate the cell membrane. Permeating cryoprotectants are generally preferred during controlled rate freezing and they preserve the entire cell including the intracellular cell organelles. These substances replace the intracellular water, thereby reducing the chances of intracellular ice formation and the damage caused by it. Whether penetrating or nonpenetrating, cryoprotectants should always be used in the right amount just enough for the tissue protection and preservation. The amount of cryoprotectants to be added for a particular geometry of tissue varies from protocol to protocol depending on the preservation technique being used. 
2.4.2. Use of Osmotic Buffer. By the time a tissue engineered cartilage construct is subjected to thawing, the tissue has already been comprised with various critical temperatures and have gone under various stresses. Therefore, CPA must be mixed with other agents that may render a protective effect on the cells and tissues during freezing and thawing. Such agents are called extenders. Citrates, FBS, FCS, and BSA are examples of such compounds. These substances are added in the CPA along with buffers like PBS and HEPES in a particular amount, such that the concentration of the resultant solution is similar to that of the physiological solutions [71].

2.4.3. Use of Antioxidants. To overcome this problem, substances which act as free radical scavengers or inhibit generations of oxidants or compounds that induce the production of antioxidants are used. Scavengers of nonradical oxidants include catalase, n-acetylcysteine, and thiols; free radicals such as superoxide, hydroxy radicals, hydrogen peroxide, hypochlorite radicals, nitric oxide, and singlet oxygen are neutralized by the free radical scavengers such as ascorbic acid, superoxide dismutase (SOD), vitamins A, E and C, glutathione, carotenoid, flavonoid, polyphenols, and saccharide; and minerals such as selenium are mixed along with the cryoprotectants to defend the cartilage against oxidation or oxidative injury and to allow the tissue to undergo multiple free thaw cycles.

\section{Conclusion}

Cryopreservation of tissue engineered cartilage is an emerging field of tissue engineering and its importance is increasingly realized owing to its potential clinical importance and the vast commercialization scope. It is envisaged to be indispensible when tissue engineering becomes a common practice among scientists, researchers, and clinicians. However, a cryopreservation-induced stress remains to be a major hurdle in the effective application of the tissue engineered cartilages, and overcoming these stresses may enhance the success of cartilage cryopreservation. The problem faced during the cryopreservation of tissue engineered cartilage constructs is not limited to the maintenance of chondrocyte viability but, is also faced in maintaining functionality.

\section{References}

[1] K. Baker, J. Goggins, H. Xie et al., "A randomized crossover trial of a wedged insole for treatment of knee osteoarthritis," Arthritis and Rheumatism, vol. 56, no. 4, pp. 1198-1203, 2007.

[2] B. D. Furman, S. A. Olson, and F. Guilak, "The development of posttraumatic arthritis after articular fracture," Journal of Orthopaedic Trauma, vol. 20, no. 10, pp. 719-747, 2006.

[3] R. Sharma, G. K. Law, K. Rekieh et al., "A novel method to measure cryoprotectant permeation into intact articular cartilage," Cryobiology, vol. 54, no. 2, pp. 196-203, 2007.

[4] J. Y. Bae, K. Matsumura, S. Wakitani, A. Kawaguchi, S. Tsutsumi, and S.-H. Hyon, "Beneficial storage effects of epigallocatechin3-o-gallate on the articular cartilage of rabbit osteochondral allografts," Cell Transplantation, vol. 18, no. 5, pp. 505-512, 2009.
[5] S. K. Williams, D. Amiel, S. T. Ball et al., "Prolonged storage effects on the articular cartilage of fresh human osteochondral allografts," Journal of Bone and Joint Surgery A, vol. 85, no. 11, pp. 2111-2120, 2003.

[6] J. Bakhach, "The cryopreservation of composite tissues: principles and recent advancement on cryopreservation of different type of tissues," Organogenesis, vol. 5, no. 3, pp. 119-126, 2009.

[7] W. F. Enneking and E. R. Mindell, "Observations on massive retrieved human allografts," Journal of Bone and Joint Surgery A, vol. 73, no. 8, pp. 1123-1142, 1991.

[8] M. Salai, U. Givon, Y. Messer, and R. von Versen, "Electron microscopic study on the effects of different preservation methods for meniscal cartilage," Annals of Transplantation, vol. 2, no. 1, pp. 52-54, 1997.

[9] G. Cetinkaya and S. Arat, "Cryopreservation of cartilage cell and tissue for biobanking," Cryobiology, vol. 63, no. 3, pp. 292-297, 2011.

[10] J. D. Boer, C. V. Blitterswijk, P. Thomsen et al., "Chapter 13: cryobiology," in Tissue Engineering, Academic Press, 2008.

[11] S. C. Chan, S. K. Lam, V. Y. Leung, D. Chan, K. D. Luk, and K. $\mathrm{M}$. Cheung, "Minimizing cryopreservation-induced loss of disc cell activity for storage of whole intervertebral discs," European Cells \& Materials, vol. 19, pp. 273-283, 2010.

[12] K. D. Luk, D. K. Ruan, D. S. Lu, and Z. Q. Fei, "Fresh frozen intervertebral disc allografting in a bipedal animal model," Spine, vol. 28, no. 9, pp. 864-869, 2003.

[13] J. Bujia, D. Kremer, H. Sudhoff, E. Viviente, C. Sprekelsen, and E. Wilmes, "Determination of viability of cryopreseved cartilage grafts," European Archives of Otorhinolaryngol, vol. 252, no. 1, pp. 30-34, 1995.

[14] C. A. Acosta, I. Izal, P. Ripalda, and F. Forriol, "Cell viability and protein composition in cryopreserved cartilage," Clinical Orthopaedics and Related Research, no. 460, pp. 234-239, 2007.

[15] D. E. Pegg, M. C. Wusteman, and L. Wang, "Cryopreservation of articular cartilage-part 1: conventional cryopreservation methods," Cryobiology, vol. 52, no. 3, pp. 335-346, 2006.

[16] Y. C. Song, F. G. Lightfoot, Z. Chen, M. J. Taylor, and K. G. M. Brockbank, "Vitreous preservation of rabbit articular cartilage," Cell Preservation Technology, vol. 2, no. 1, pp. 67-74, 2004.

[17] Y. C. Song, H. A. Yuehuei, K. K. Qian et al., "Ice-free cryopreservation of articular cartilage," Tissue Engineering, vol. 8, no. 6, p. 1181, 2002.

[18] B. Weber, M. Y. Emmert, R. Schoenauer, C. Brokopp, L. Baumgartner, and S. P. Hoerstrup, "Tissue engineering on matrix: future of autologous tissue replacement," Seminars in Immunopathology, vol. 33, no. 3, pp. 307-315, 2011.

[19] J. Leor, Y. Amsalem, and S. Cohen, "Cells, scaffolds, and molecules for myocardial tissue engineering," Pharmacology and Therapeutics, vol. 105, no. 2, pp. 151-163, 2005.

[20] V. Vindigni, R. Cortivo, L. Iacobellis, G. Abatangelo, and B. Zavan, "Hyaluronan benzyl ester as a scaffold for tissue engineering," International Journal of Molecular Sciences, vol. 10, no. 7, pp. 2972-2985, 2009.

[21] A. G. Mikos, S. W. Herring, P. Ochareon et al., "Engineering complex tissues," Tissue Engineering, vol. 12, no. 12, pp. 33073339,2006

[22] K. A. Athanasiou, E. M. D. Davis, and C. H. Jerry, Articular Cartilage Tissue Engineering, Synthesis Lectures on Tissue Engineering, 2009. 
[23] D. S. Vara, H. J. Salacinski, R. Y. Kannan, L. Bordenave, G. Hamilton, and A. M. Seifalian, "Cardiovascular tissue engineering: state of the art," Pathologie Biologie, vol. 53, no. 10, pp. 599612, 2005.

[24] M. Risbud, "Tissue engineering: implications in the treatment of organ and tissue defects," Biogerontology, vol. 2, no. 2, pp. 117$125,2001$.

[25] J. van der Valk, D. Mellor, R. Brands et al., "The humane collection of fetal bovine serum and possibilities for serum-free cell and tissue culture," Toxicology in Vitro, vol. 18, no. 1, pp. 1-12, 2004.

[26] C.-Y. Liu, Y.-H. Liu, S.-M. Lin et al., "Apoptotic neutrophils undergoing secondary necrosis induce human lung epithelial cell detachment," Journal of Biomedical Science, vol. 10, no. 6, pp. 746-756, 2003.

[27] H. Jaeschke and J. J. Lemasters, "Apoptosis versus oncotic necrosis in hepatic ischemia/reperfusion injury," Gastroenterology, vol. 125, no. 4, pp. 1246-1257, 2003.

[28] W. Wilson, C. C. Van Donkelaar, B. Van Rietbergen, and R. Huiskes, "A fibril-reinforced poroviscoelastic swelling model for articular cartilage," Journal of Biomechanics, vol. 38, no. 6, pp. 1195-1204, 2005.

[29] A. Maroudas and P. Bullough, "Permeability of articular cartilage," Nature, vol. 219, no. 5160, pp. 1260-1261, 1968.

[30] F. Guilak, G. R. Erickson, and H. P. Ting-Beall, "The effects of osmotic stress on the viscoelastic and physical properties of articular chondrocytes," Biophysical Journal, vol. 82, no. 2, pp. 720-727, 2002.

[31] F. Guilak, B. C. Meyer, A. Ratcliffe, and V. C. Mow, "The effects of matrix compression on proteoglycan metabolism in articular cartilage explants," Osteoarthritis and Cartilage, vol. 2, no. 2, pp. 91-101, 1994.

[32] A. Maroudas, "Physiochemical properties of articular cartilage," in Adult Articular Cartilage, M. A. R. Freeman, Ed., pp. 215-290, Pitman Medical, Tunbridge Wells, UK, 1979.

[33] F. Guilak, "Compression-induced changes in the shape and volume of the chondrocyte nucleus," Journal of Biomechanics, vol. 28, no. 12, pp. 1529-1541, 1995.

[34] M. Wong, P. Wuethrich, M. D. Buschmann, P. Eggli, and E. Hunziker, "Chondrocyte biosynthesis correlates with local tissue strain in statically compressed adult articular cartilage," Journal of Orthopaedic Research, vol. 15, no. 2, pp. 189-196, 1997.

[35] J. Schiller, M. Wagner, A. Werner, K. Arnold, and W. Grunder, "The effect of temperature on the storage of porcine articular cartilage-an NMR-Study," Biomedizinische Technik/Biomedical Engineering, vol. 40, no. 1-2, pp. 19-23, 1995.

[36] N. Mukherjee, Z. Chen, A. Sambanis, and Y. Song, "Effects of cryopreservation on cell viability and insulin secretion in a model Tissue-Engineered Pancreatic Substitute (TEPS)," Cell Transplantation, vol. 14, no. 7, pp. 449-456, 2005.

[37] N. M. Jomha, P. C. Anoop, and L. E. McGann, "Intramatrix events during cryopreservation of porcine articular cartilage using rapid cooling," Journal of Orthopaedic Research, vol. 22, no. 1, pp. 152-157, 2004.

[38] S. Zheng, Y. Xia, A. Bidthanapally, F. Badar, I. Ilsar, and N. Duvoisin, "Damages to the extracellular matrix in articular cartilage due to cryopreservation by microscopic magnetic resonance imaging and biochemistry," Magnetic Resonance Imaging, vol. 27, no. 5, pp. 648-655, 2009.

[39] K. Muldrew, K. Novak, H. Yang, R. Zernicke, N. S. Schachar, and L. E. McGann, "Cryobiology of articular cartilage: ice morphology and recovery of chondrocytes," Cryobiology, vol. 40, no. 2, pp. 102-109, 2000.

[40] T. M. Farooque, Biochemical and Mechanical Stimuli for Improved Material Properties and Preservation of TissueEngineered Cartilage, Georgia Institute of Technology, 2008.

[41] K. Y. Teo, J. C. Dutton, and B. Han, "Spatiotemporal measurement of freezing-induced deformation of engineered tissues," Journal of Biomechanical Engineering, vol. 132, no. 3, article 031003, 8 pages, 2010.

[42] R. H. J. Das, G. J. V. M. Van Osch, M. Kreukniet, J. Oostra, $\mathrm{H}$. Weinans, and H. Jahr, "Effects of individual control of $\mathrm{pH}$ and hypoxia in chondrocyte culture," Journal of Orthopaedic Research, vol. 28, no. 4, pp. 537-545, 2010.

[43] P. I. Milner, R. J. Wilkins, and J. S. Gibson, "Cellular physiology of articular cartilage in health and disease," in Principles of Osteoarthritis- Its Definition, Character, Derivation and Modality-Related Recognition, pp. 567-590, Intech, 2012.

[44] M. D. Valeria, J. S. Mort, S. Leverty et al., "Cleavage of telopeptides causes the depolymerisation of fibrillar collagen network, and cleavage of the triple helix present in collagen results in depolymerisation accompanied by denaturation," The American Journal of Pathology, vol. 173, p. 1, 2008.

[45] Y. Zheng, H. Lv, Y. Wang, H. Lu, L. Qing, and T. Xi, "Performance of novel bioactive hybrid hydrogels in vitro and in vivo used for artificial cartilage," Biomedical Materials, vol. 4, no. 1, Article ID 015015, 2009.

[46] P. Mazur, "Freezing of living cells: mechanisms and implications," The American Journal of Physiology, vol. 247, no. 3, pp. C125-C142, 1984.

[47] B. Han, E. D. Grassl, V. H. Barocas, J. E. Coad, and J. C. Bischof, "A cryoinjury model using engineered tissue equivalents for cryosurgical applications," Annals of Biomedical Engineering, vol. 33, no. 7, pp. 972-982, 2005.

[48] A. Mobasheri, "Ion transport in chondrocytes: membrane transporters involved in intracellular ion homeostasis and the regulation of cell volume, free $[\mathrm{Ca} 2+]$ and $\mathrm{pH}$," Histology and Histopathology, vol. 13, no. 3, pp. 893-910, 1998.

[49] C. Z. Jin, J.-H. Cho, B. H. Choi et al., "The maturity of tissue-engineered cartilage in vitro affects the repairability for osteochondral defect," Tissue Engineering A, vol. 17, no. 23-24, pp. 3057-3065, 2011

[50] R. Vasita and D. S. Katti, "Nanofibers and their applications in tissue engineering," International Journal of Nanomedicine, vol. 1, no. 1, pp. 15-30, 2006.

[51] M. R. Seddighi, D. J. Griffon, D. J. Schaeffer, B. A. Fadl-Alla, and J. A. C. Eurell, "The effect of chondrocyte cryopreservation on cartilage engineering," Veterinary Journal, vol. 178, no. 2, pp. 244-250, 2008.

[52] R. F. Loeser, "Chondrocyte integrin expression and function," Biorheology, vol. 37, no. 1-2, pp. 109-116, 2000.

[53] D. L. Reid, M. B. Aydelotte, and J. Mollenhauer, "Cell attachment, collagen binding, and receptor analysis on bovine articular chondrocytes," Journal of Orthopaedic Research, vol. 18, no. 3, pp. 364-373, 2000.

[54] C. Ruiz-Romero, V. Calamia, J. Mateos et al., "Mitochondrial dysregulation of osteoarthritic human articular chondrocytes analyzed by proteomics: a decrease in mitochondrial superoxide dismutase points to a redox imbalance," Molecular and Cellular Proteomics, vol. 8, no. 1, pp. 172-189, 2009.

[55] G. K. Gorti, J. Lo, S. Falsafi et al., "Cartilage tissue engineering using cryogenic chondrocytes," Archives of OtolaryngologyHead and Neck Surgery, vol. 129, no. 8, pp. 889-893, 2003. 
[56] K. Mansfield, C. C. Teixeira, C. S. Adams, and I. M. Shapiro, "Phosphate ions mediate chondrocyte apoptosis through a plasma membrane transporter mechanism," Bone, vol. 28, no. 1, pp. 1-8, 2001.

[57] K. A. Almansoori, V. Prasad, J. F. Forbes et al., "Cryoprotective agent toxicity interactions in human articular chondrocytes," Cryobiology, vol. 64, no. 3, pp. 185-191, 2012.

[58] E. A. Kennedy, D. S. Tordonado, and S. M. Duma, "Effects of freezing on the mechanical properties of articular cartilage," Biomedical Sciences Instrumentation, vol. 43, pp. 342-347, 2007.

[59] T. L. Willett, R. Whiteside, P. M. Wild, U. P. Wyss, and T. Anastassiades, "Artefacts in the mechanical characterization of porcine articular cartilage due to freezing," Proceedings of the Institution of Mechanical Engineers H, vol. 219, no. 1, pp. 23-29, 2005.

[60] K. A. Athanasiou, M. P. Rosenwasser, J. A. Buckwalter, T. I. Malinin, and V. C. Mow, "Interspecies comparisons of in situ intrinsic mechanical properties of distal femoral cartilage," Journal of Orthopaedic Research, vol. 9, no. 3, pp. 330-340, 1991.

[61] A. J. Kerin, M. R. Wisnom, and M. A. Adams, "The compressive strength of articular cartilage," Proceedings of the Institution of Mechanical Engineers H, vol. 212, no. 4, pp. 273-280, 1998.

[62] A. de Wolf, Future Directions in Human Cryopreservation Combinational Pharmacotherapy, 2007.

[63] K. Muldrew, M. Hurtig, K. Novak, N. Schachar, and L. E. McGann, "Localization of freezing injury in articular cartilage," Cryobiology, vol. 31, no. 1, pp. 31-38, 1994.

[64] X. Xu, Z. F. Cui, R. J. Wilkins, and J. P. G. Urban, "Intracellular $\mathrm{pH}$ changes in isolated bovine articular chondrocytes during the loading and removal of cryoprotective agents," Cryobiology, vol. 46, no. 2, pp. 161-173, 2003.

[65] A. Abazari Torqabeh, Modeling the transport of cryoprotective agents in articular cartilage for cryopreservation [Ph.D. thesis], 2011.

[66] E. Wernike, Z. Li, M. Alini, and S. Grad, "Effect of reduced oxygen tension and long-term mechanical stimulation on chondrocyte-polymer constructs," Cell and Tissue Research, vol. 331, no. 2, pp. 473-483, 2008.

[67] M. Deberg, A. Labasse, S. Christgau et al., "New serum biochemical markers (Coll 2-1 and Coll 2-1 $\mathrm{NO}_{2}$ ) for studying oxidative-related type II collagen network degradation in patients with osteoarthritis and rheumatoid arthritis," Osteoarthritis and Cartilage, vol. 13, no. 3, pp. 258-265, 2005.

[68] F. Zaman, D. Chrysis, K. Huntjens, B. Fadeel, and L. Sävendahl, "Ablation of the pro-apoptotic protein bax protects mice from glucocorticoid-induced bone growth impairment," PLoS ONE, vol. 7, no. 3, article e33168, 2012.

[69] D. Acehan, X. Jiang, D. G. Morgan, J. E. Heuser, X. Wang, and C. W. Akey, "Three-dimensional structure of the apoptosome: implications for assembly, procaspase- 9 binding, and activation," Molecular Cell, vol. 9, no. 2, pp. 423-432, 2002.

[70] C. Polge, A. U. Smith, and A. S. Parkes, "Revival of spermatozoa after vitrification and dehydration at low temperatures," Nature, vol. 164, no. 4172, p. 666, 1949.

[71] Y. Orief, A. Schultze-Mosgau, K. Dafopoulos, and S. Al-Hasani, "Vitrification: will it replace the conventional gamete cryopreservation techniques?" Middle East Fertility Society Journal, vol. 10, no. 3, pp. 171-184, 2005. 


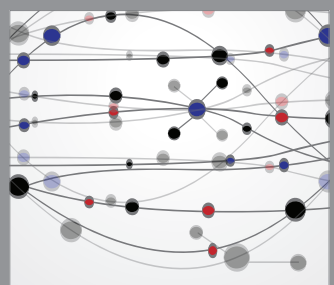

The Scientific World Journal
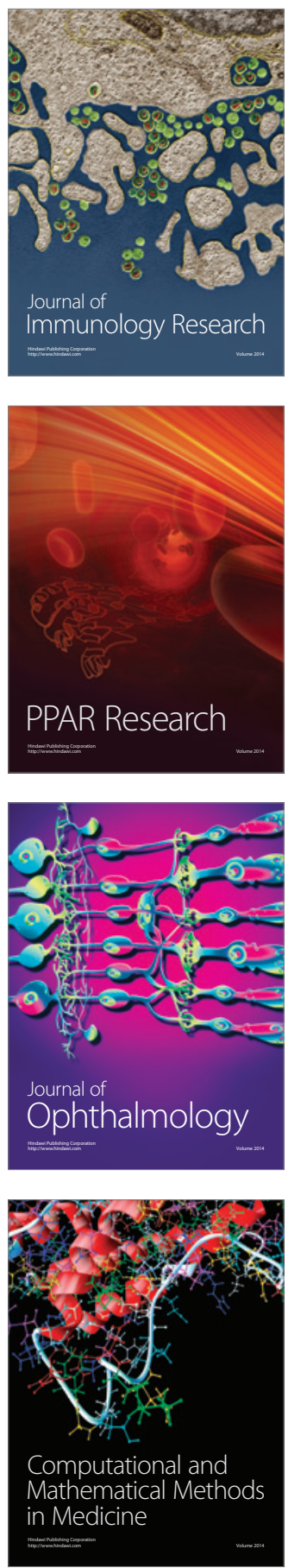

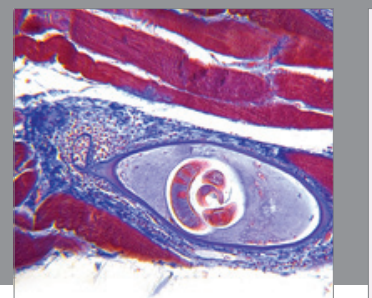

Gastroenterology

Research and Practice
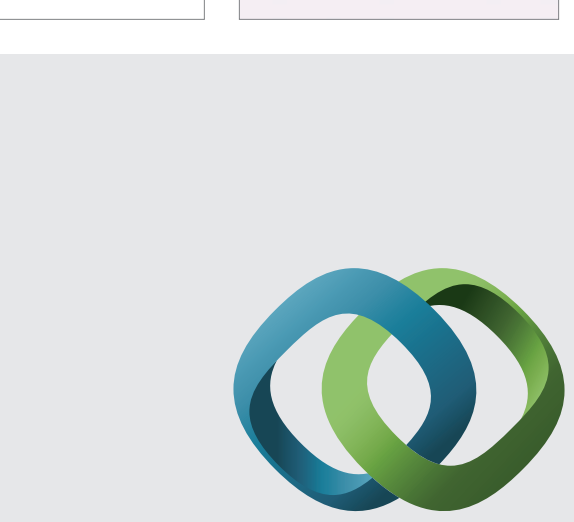

\section{Hindawi}

Submit your manuscripts at

http://www.hindawi.com
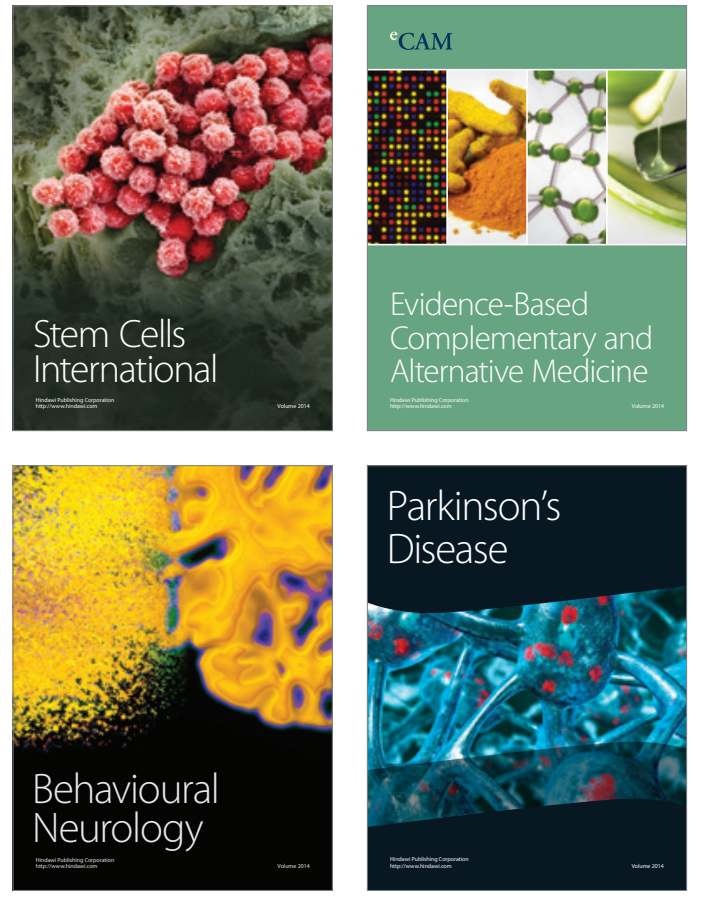
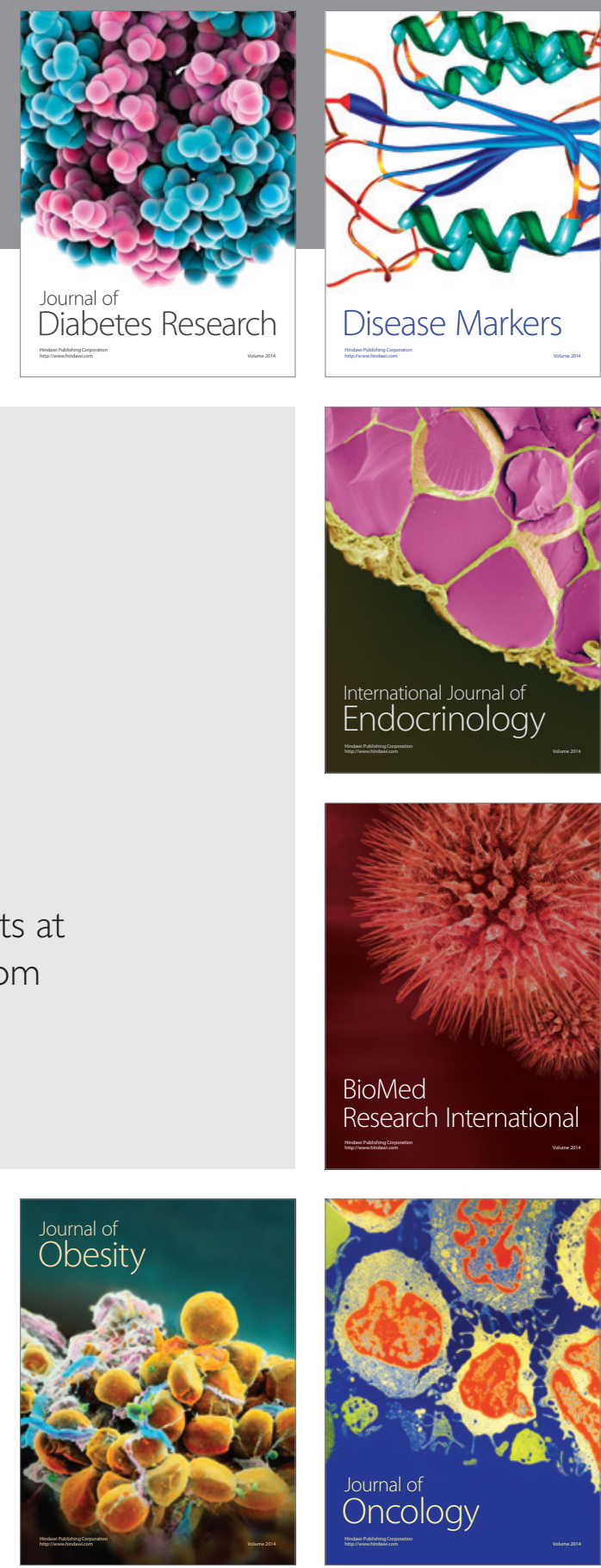

Disease Markers
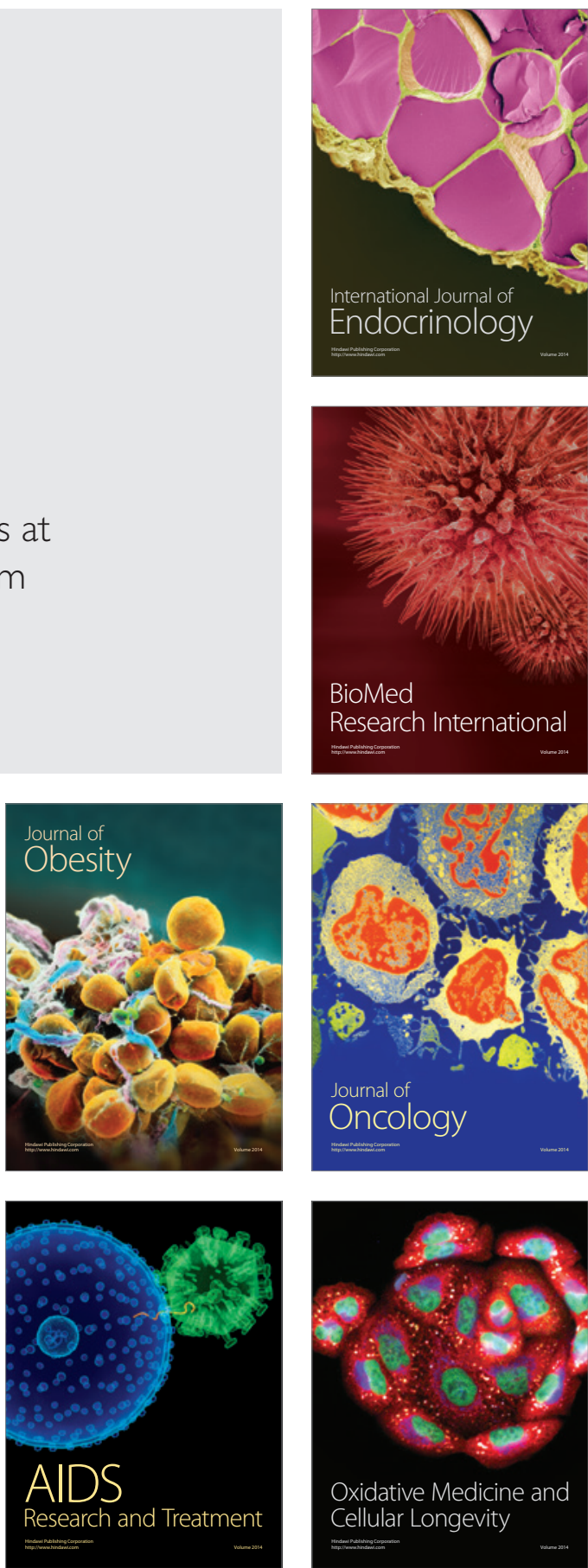